\title{
Mechanical colon cleansing device in patients with chronic constipation: An experimental study
}

\author{
Mahdi Alemrajabi $^{1^{*} \mathbb{D}}$, Seyedeh Fahimeh Shojae ${ }^{1}$, Mohammad Moradi $^{1 * \mathbb{D}}$, Amin Dehghanian $^{1}$, Amirreza Ehsani $^{1}$, \\ Seyed Soroosh Valinia ${ }^{1}$
}

Received: 20 Jun 2019

Published: 30 Jun 2021

\begin{abstract}
Background: Constipation is one of the most common gastrointestinal discomforts that affects various age groups in humans. Different mechanical cleansing devices have been introduced yet. However, they are very expensive and not available in our country.

Methods: This was a pilot experimental trial. Fifteen patients with eligible ROME III criteria and at least two years of chronic constipation and resistant to medical therapy entered the study. Wexner and Longo's scores were checked before and after using the "Roodeshur" device. Data entered SPSS 16 and analyzed using T-test. A p value below 0.05 was considered as a statistically significant difference.

Results: Five patients were female and 10 males. The mean age of patients was $53.56 \pm 18.34$ years. There was a significant difference regarding intestinal movement before and after using the device $(\mathrm{p}<0.001)$. Wexner's score dlecreased after the intervention with a significant difference $(\mathrm{p}<0.001)$.

Conclusion: Our mechanical cleansing device (Roodeshur) was effective and safe for patients with resistance constipation. No complication occurred. Due to its low cost and easy access in our country, it can be recommended for otther patients as well. However, more studies with a larger sample size are recommended.
\end{abstract}

Keywords: Chronic Constipation, Mechanical Cleansing, Wexner

Conflicts of Interest: None declared

Funding: This device was manufactured by the author and supported by the Iranian Innovations and Inventions Organization.

*This work has been published under CC BY-NC-SA 1.0 license.

Copyright $\odot$ Iran University of Medical Sciences

Cite this article as: Alemrajabi M, Shojae SF, Moradi M, Dehghanian A, Ehsani A, Valinia SS. Mechanical colon cleansing device in patients with chronic constipation: An experimental study. Med J Islam Repub Iran. 2021 (30 Jun);35:84. https://doi.org/10.47176/mjiri.35.84

\section{Introduction}

Constipation is one of the most common gastrointestinal discomforts that affects various age groups in humans (1). Epidemiological studies showed that the prevalence of constipation is $2 \%$ to $27 \%$ in the general population $(1,2)$.

The Rome criteria for chronic constipation is defined as follows; symptoms must begin at least 6 months before the diagnosis, and all the criteria should have happened in the recent three months, there should be no sign of IBS (Irritable Bowel Syndrome) and no history of loose feces

\footnotetext{
Corresponding author: Dr Mahdi Alemrajabi, alemrajabi.m@iums.ac.ir Dr Mohammad Moradi, Moradi.mo@iums.ac.ir
}

1. Firoozgar Clinical Research and Development Center (FCRDC), Iran University of Medical Sciences, Tehran, Iran without using laxatives, less than 3 times defecation per week, existence of 2 or more symptoms in at least $25 \%$ of defecation times. Also, defecation with heavy pressure, dry and stony feces, incomplete sense of defecation, sense of obstructive defecation, being dependent on external maneuvers to defecate, feeling of obstructed rectum and abdominal distention are symptoms that could lead to constipation diagnosis $(3,4)$.

If there is no primary or secondary cause for constipa-

$\uparrow$ What is "already known" in this topic:

ODS patients who are resistant to medical therapy must undergo further surgical (rectopexy) or non-surgical advanced measures. Many mechanical cleansing devices have been recently introduced for patients with resistant constipation. Nonetheless, they are expensive and not available in Iran.

$\rightarrow$ What this article adds:

Our study is the primary trial of the "Roodeshur" device in Iran. This device was built in Iran and is now available for patients with resistant constipation at a low cost. 
tion, idiopathic constipation is suggested (5).

Idiopathic constipation is divided into different types such as constipation with normal transient time or slow transient time and etc. Constipation in ODS (Obstructive Defecatory Syndrome) is usually associated with a normal transient type (6). This is the most common type of chronic constipation. Patients with ODS mostly come with normal transient constipation but they also have a delay in defecation of the sigmoid part (7). Some patients present with symptoms like dilated rectum, huge rectocele, enterocele, rectal prolapse, rectocele and enterocele and perineal syndrome (9). Currently, ODS is the cause of pain in a great number of patients all around the world and there are so many approaches to treat patients such as surgical and non-surgical procedures.

In surgical approaches, the surgeon tries to modify structural disturbances while non-surgical operations focus on improving patient's function or alleviate the pain they experience. These approaches include enough hydration and fiber intake, increase of physical activities, biofeedback learning and etc. (10).

Studies demonstrated that $50 \%$ of patients with chronic constipation were not satisfied by using a laxative or other conservative treatments and they were more prone to use invasive approaches $(11,12)$. Mechanical washing of intestinal lumen is one of the new approaches used after the failure of the first line of medical treatment. In this approach, tepid water is used for washing and is transferred by a catheter from the anus to the rectum, thus feces are evacuated. Currently, there are many devices available with different shapes and brands in the market. However, they are expensive and not available in the country. There- fore, we tried to build a similar device in Iran to overcome patients' problems. We aimed to assess the efficacy and safety of this device in an Iranian population.

\section{Methods}

This was a pilot experimental trial. Fifteen patients with eligible ROME III criteria and at least 2 years of chronic constipation resistant to medical therapy were included. LONGO score for ODS was more than 4-6. All patients had undergone a complete course of biofeedback before enrolment.

Exclusion criteria were mental and physical disability, patients who could not provide self-care or not able to speak the Persian language. A written informed consent was obtained from eligible patients. Personal information and demographic data of patients were collected by interview. Data included name, family name, age, gender, underlying diseases, duration of constipation, past surgical procedure, defecation time during a day, drug history, laboratory results and imaging findings. Then patients were asked to complete two Wexner and LONGO questionnaires before and after the intervention with the "Roodeshur" device (Fig. 1). Also, patients were in contact with the research team thoroughly during the intervention by phone calls or visits. After 3 months of using the device, they were invited and WEXNER and LONGO tests were filled again.

\section{Data analysis}

Demographic data were recorded in specific sheets. Wexner and Longo's scores were recorded before entering the study and three months after using the device. Data

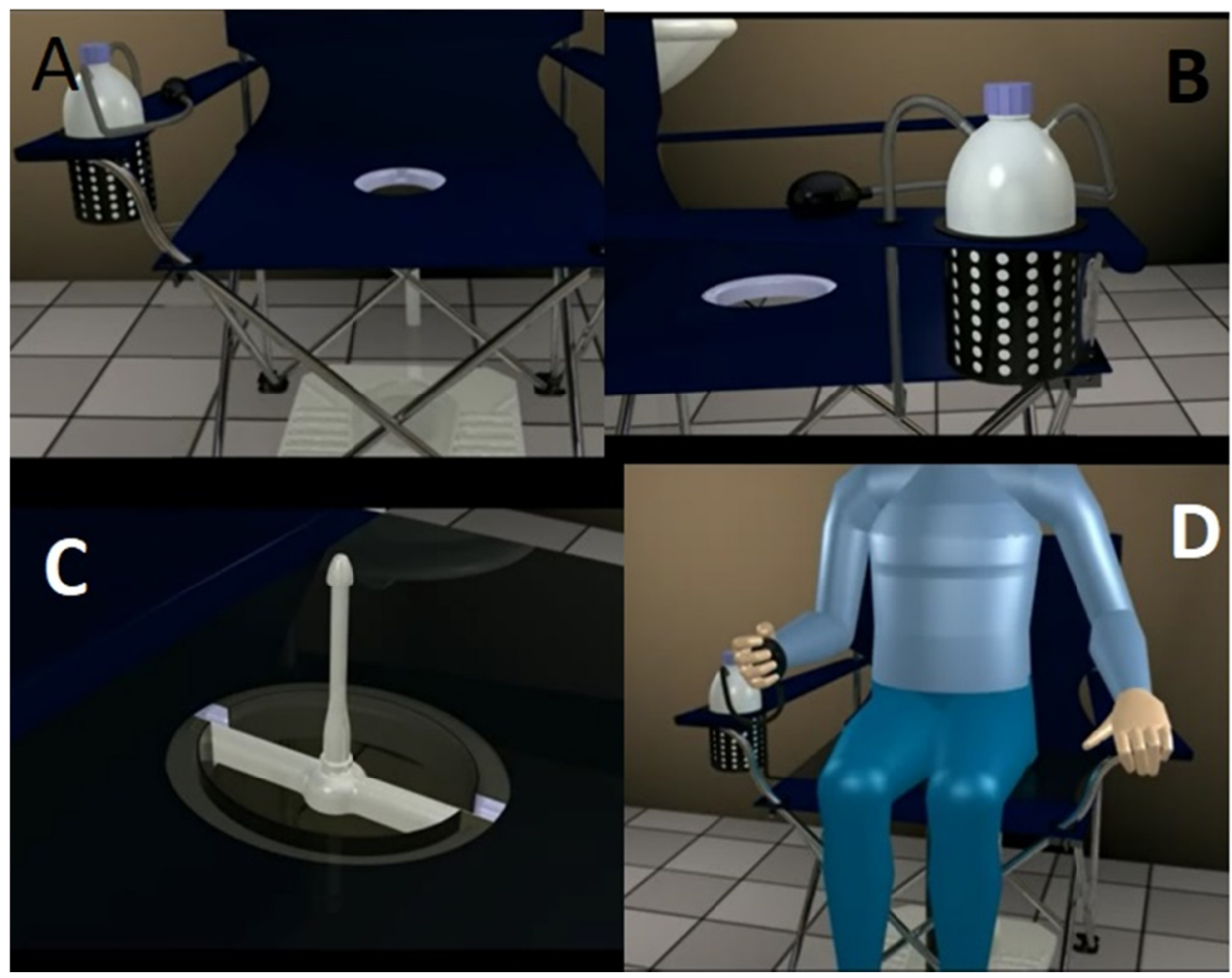

Fig. 1. Schematic View of the Device. A and B Show an Overview of the Device. C. The Enema Tube Fixed on the Chair that Pushes Water Through the Rectum. D. Patient Sitting on the Chair 
entered SPSS 16 (SPSS Inc. Chicago, Il, The USA). Descriptive and analytic tests were used. Paired T-test was used to assess mean values before and after the intervention. A p value below 0.05 was considered as a statistically significant difference.

\section{Ethical approval}

The device has been registered as an invention in the Iranian Registry of Inventions (Registration Code; 89378). However, ethical approval was obtained from Iran University of Medical Sciences ethics committees (Code; IR.IUMS.FMD.REC.1396.8811215265). All the steps of our trial were performed according to the Helsinki Declaration. Also, a written informed consent was obtained from each patient before enrolment.

\section{Results}

Fifteen patients entered the study. Five patients were females and 10 males. The mean $\pm \mathrm{SD}$ age of patients was $53.56 \pm 18.34$ years. Patients' demographic characteristics are shown in Table 1. There was a meaningful difference regarding intestinal movement before and after using the device $(\mathrm{p}<0.001)$. However, painful attempt for defecation after using the device was significantly reduced $(\mathrm{p}<0.001)$. Regarding feeling of incomplete evacuation, there was a statistically meaningful difference after the intervention $(p<0.001)$. However, patients reported having less abdominal pain after using the device $(p<0.001)$. Moreover, the time to stay in the toilet after using the device decreased statistically $(p<0.001)$. Besides, digitation for evacuation decreased significantly after the intervention $(p<0.001)$. Number of unsuccessful attempts to evacuation within 24 hours decreased significantly $(\mathrm{p}<0.001)$. Also, all patients reported offering the device to others. Table 2 shows the mean values of variables before and after the treatment.

Table 2 presents items of Wexner and Longo questionnaires. Therefore, it is evident that both scales decreased significantly after using the device.

\section{Discussion}

Colonic irrigation has been recently shown to have beneficial effects on defecatory disorders (13-15). And its role has been investigated in different types of constipations, such as irritable bowel syndrome. According to our knowledge, there is no trial in the literature on the effect of mechanical irrigation on the obstructive defecatory syndrome. Also, these devices are not available in Iran and preparing them from other abroad companies imposes
Table 1. Demographic Characteristics of Participants

\begin{tabular}{lc}
\hline Variable & Value \\
\hline Gender & $10(66.6 \%)$ \\
Male & $5(33.3 \%)$ \\
Female & $53.56 \pm 18.34$ \\
Age (Mean \pm SD), years & \\
Education & $6(40 \%)$ \\
Diploma or lower & $6(40 \%)$ \\
Bachelor & $3(20 \%)$ \\
Master or higher & \\
Pregnancy history & $1(20 \%)$ \\
Nil & $2(40 \%)$ \\
one & $1(20 \%)$ \\
two & $1(20 \%)$ \\
3 or more &
\end{tabular}

high costs for patients. Therefore, we tried to build a similar device in our country with low costs.

In a study performed by Hsu et al. 18 patients with IBS were studied. They concluded that colonic irrigation is harmless and was able to lessen abdominal pain, constipation, and diarrhea in patients with IBS. Most patients in their study were satisfied with improving their signs and symptoms after using mechanical colonic irrigation (16).

Their results are in accordance with ours in which patients reported better feeling after complete evacuation and consistency of their defecation was improved.

Safety of mechanical cleansing is of great importance, and there are some reports of colonic perforation after misusing of patients $(17,18)$. Fortunately, this did not occur in our patients because the maximum pressure of the "Roodeshur" cuff device is limited to $15 \mathrm{mmHg}$. The cuff cannot produce higher pressures avoiding such complications. Bowel perforation after using rectal irrigation has been reported as $0.002 \%$ in different studies which is extremely low, which shows the device safety in accordance with our study (19). Device setup to produce a standard maximum pressure and training patients to use the device correctly reduces the rate of perforation significantly. However, close contact between our researcher team with patients removed all their ambiguities regarding the use of the device and ensured its safety.

However, presence of underlying disorders like solitary rectal ulcer or colon cancer may increase the rate of perforation, which were excluded from our trial before the study by complete colonoscopy study for all patients.

Amebiasis cross-infection between patients has been previously reported by using colon irrigation device by several patients, which was avoided in our study, as each one used his or her own device (20). Moreover, the container capacity of our device is limited to one liter, which

Table 2. Mean Values of Variables Before and After the Intervention

\begin{tabular}{lcc}
\hline Variable & $\begin{array}{c}\text { Before the treatment } \\
\text { (Mean } \pm \text { SD) }\end{array}$ & $\begin{array}{c}\text { After the treatment } \\
(\mathrm{Mean} \pm \mathrm{SD})\end{array}$ \\
\hline Intestinal movement & $3.8125 \pm 1.60078$ & $2.1250 \pm 0.7188$ \\
A painful attempt of evacuate & $3.8750 \pm 0.34157$ & $2.25 \pm 0.4472$ \\
Feeling of incomplete evacuation & $3.9375 \pm 0.5737$ & $<.1875 \pm 0.5439$ \\
Abdominal pain & $3.5 \pm 0.730$ & $<0.001$ \\
Time to stay in the toilet & $3.1875 \pm 0.83417$ & $2.3125 \pm 0.60208$ \\
Aid for evacuation & $2.25 \pm 0.577$ & $1.3125 \pm 0.60208$ \\
Number of unsuccessful attempts to evacuate within 24 hours & $3.3125 \pm 1.014$ & $1.4375 \pm 0.51235$ \\
\hline
\end{tabular}


ensures its safety as well. No imbalance of electrolytes occurred after using it. The amount of water absorbed by the gut was not significant and the patients were able to defecate while using the device. Almost all patients mentioned that they want to recommend it to their friends. However, some patients did not use the device anymore after a complete response.

Other methods have been used for patients with chronic constipation, including sacral nerve stimulation and the Malone antegrade continence enema for patients with unremitting constipation and defecation disorders, reported to improve patients' quality of life (21-23).

Our device named "Roodeshur" is similar to other available devices in the market regarding its function and general concept. However, our device was designed and produced with fewer price. Also, they were prone to suggest the device to other patients as well. However, the device was designed to be used with the Eastern (Iranian) toilet easily, and a video clip of how to use the device was given to all patients for easy apply. (The video is available upon the editors or readers request)

Our study showed the efficacy of using this device for patients with the obstructive defecatory syndrome. Those patients with refractory constipation who did not respond to regular treatments can be good candidates for using this cheap and user-friendly device.

Wexner and Longo's scores improved significantly after using the device. It is recommended to perform more studies with a larger sample size to assess other aspects of using the device in these patients or other disorders of chronic constipation as well.

\section{Conclusion}

Our mechanical cleansing device (Roodeshur) was effective and safe for patients with resistance constipation. No complication occurred. Due to its low cost and easy access in our country, it can be recommended for other patients as well.

\section{Acknowledgement}

We would like to thank general surgery residents of Firoozgar hospital who helped us by contacts with patients to answer their questions.

\section{Conflict of Interests}

The authors declare that they have no competing interests.
6. Foxx-Orenstein AE, McNally MA, Odunsi ST. Update on constipation: one treatment does not fit all. Clevel Clin J Med. 2008;75(11):813-24.

7. Wald A. Severe constipation. Clinical gastroenterology and hepatology: the official clinical practice. Am J Gastroenterol 2005;3(5):432-5

8. Toglia MR. Pathophysiology of anorectal dysfunction. Obstet Gynecol Clin North Am. 1998;25(4):771-81, vi.

9. Andrews CN, Storr M. The pathophysiology of chronic constipation. Can J Gastroenterol Hepatol. 2011;25(Suppl B):16B-21B.

10. Johanson JF. Review of the Treatment Options for Chronic Constipation. Medscape J Med. 2007;9(2):25-.

11. Wald A, Scarpignato C, Mueller-Lissner S, Kamm MA, Hinkel U, Helfrich I, et al. A multinational survey of prevalence and patterns of laxative use among adults with self-defined constipation. Aliment Pharmacol Ther. 2008;28(7):917-30.

12. Muller-Lissner S, Tack J, Feng Y, Schenck F, Specht Gryp R. Levels of satisfaction with current chronic constipation treatment options in Europe - an internet survey. Aliment Pharmacol Ther. 2013;37(1):13745.

13. Pizzetti D, Annibali R, Bufo A, Pescatori M. Colonic hydrotherapy for obstructed defeation. Colorectal Dis. 2005;7(1):107-8.

14. Juul T, Christensen P. Prospective evaluation of transanal irrigation for fecal incontinence and constipation. Tech Coloproctol. 2017;21(5):363-71.

15. Etherson KJ, Minty I, Bain IM, Cundall J, Yiannakou Y. Transanal Irrigation for Refractory Chronic Idiopathic Constipation: Patients Perceive a Safe and Effective Therapy. Gastroenterol Res Pract. 2017;2017:3826087

16. Hsu HH, Leung WH, Hu GC. Treatment of irritable bowel syndrome with a novel colonic irrigation system: a pilot study. Tech Coloproctol. 2016;20(8):551-557.

17. Niv G, Grinberg T, Dickman R, Wasserberg N, Niv Y. Perforation and mortality after cleansing enema for acute constipation are not rare but are preventable. Int J Gen Med. 2013;6:323-328.

18. Lundy JB, Gadacz TR. Massive fecal impaction presenting with megarectum and perforation of a stercoral ulcer at the rectosigmoid junction. South Med J. 2006;99:525-527.

19. Christensen P, Krogh K, Buntzen S, Payandeh F, Laurberg S. Longterm outcome and safety of transanal irrigation for constipation and fecal incontinence. Dis Colon Rectum. 2009;52:286-292.

20. Christensen P, Krogh K, Buntzen S, Payandeh F, Laurberg S. Longterm outcome and safety of transanal irrigation for constipation and fecal incontinence. Dis Colon Rectum. 2009;52:286-292.

21. Lundby L, Krogh K, Buntzen S, Laurberg S. Temporary sacral nerve stimulation for treatment of irritable bowel syndrome: a pilot study. Dis Colon Rectum. 2008;51:1074-1078.

22. Sharma A, Liu B, Waudby P, Duthie GS. Sacral neuromodulation for the management of severe constipation: development of a constipation treatment protocol. Int J Colorectal Dis. 2011;226:15831587.

23. Poirier M, Abcarian $H$, Nelson R. Malone antegrade continent enema: an alternative to re section in severe defecation disorders. Dis Colon Rectum. 2007;50:22-28.

\section{References}

1. Sanchez MI, Bercik P. Epidemiology and burden of chronic constipation. Can J Gastroenterol Hepatol. 2011;25 Suppl B:11b-5b.

2. Choung RS, Locke GR, 3rd, Schleck CD, Zinsmeister AR, Talley NJ. Cumulative incidence of chronic constipation: a population-based study 1988-2003. Aliment Pharmacol Ther. 2007;26(11-12):1521-8.

3. Drossman DA. The functional gastrointestinal disorders and the Rome III process. Gastroenterology. 2006;130(5):1377-90.

4. Azizi R, Alvandipour M, Bijari A, Shoar S, Alemrajabi M. Clinical outcome after stapled transanal rectal resection for obstructed defecation syndrome: the first Iranian experience. Eur Surg. 2013;45:21.

5. Borum ML. Constipation: evaluation and management. Prim Care. 2001;28(3):577-90, vi. 